\title{
Aliquid quo nibil maius diligi potest: \\ Una re-lectura agustiniana del argumento de san Anselmo
}

\author{
SALVADOR ANTUNAANO \\ Escuela Internacional de Doctorado \\ Universidad Francisco de Vitoria (Madrid) \\ s.antunano@ufv.es \\ (D) ORCID: 0000-0002-5997-6687
}

Resumen: La mayoría de los estudios sobre el argumento anselmiano del Proslogion se centran en su forma lógica. Este artículo intenta mostrar que, si se relee su fondo antropológico y teológico a la luz de la tradición agustiniana, se descubre que el argumento es consistente, y que posee un intenso carácter dramático y vivencial. Para ello, se revisará en el texto y su contexto los indicios que justifican una lectura agustiniana y se reformulará el argumento de acuerdo con ella para captar su sentido, consistencia y validez. Finalmente se resumirán las conclusiones.

Palabras clave: argumento ontológico, san Anselmo, tradición agustiniana, Proslogion, ordo amoris.

Abstract: Most of the studies on the Anselmian Argument in the Proslogion focus on its logic form. This article tries to prove that the Argument is consistent, and has an intense dramatic character if its anthropological and theological subject is analysed under the augustinian Tradition light. Thus, after an introduction, the article explores the context and the hints that support an Augustinian reading of the Argument and rewords it accordingly to that reading. Finally, the conclusions are given.

Keywords: ontological argument, saint Anselm, augustinian tradition, Proslogion, ordo amoris. 


\section{INTRODUCCIÓN}

El $^{1}$ núcleo del argumento de san Anselmo en el Proslogion ${ }^{2}$ parece estar, como es sabido, en la posible necesidad del paso del "orden intelectual" (rem esse in intellectu) al "orden de la realidad extra-mental" (rem esse in re). La posibilidad de esa conexión necesaria divide a los filósofos posteriores entre quienes están de acuerdo con el Prior de Bec y los que no. La mayoría de estudios sobre el "argumento anselmiano" (ratio Anselmi) se enfoca desde la ontología y la lógica (hasta llegar a aplicaciones a la llamada inteligencia artificial ${ }^{3}$ ), porque el punto de partida es la forma lógica del argumento y porque los términos se toman en una comprensión muy precisa: pensar es asumido como una actividad inmanente al sujeto; pensamiento/idea se toman como meros objetos de conciencia, cuya referencia con la realidad extra-mental no se ve inmediatamente necesaria sino contingente y subjetiva. Así, la lectura que desde Gaunilo se ha hecho, ha estado teñida de un trasfondo racionalista, incluso nominalista, que afecta también, a veces, a quienes defienden el argumento.

El presente artículo ofrece una lectura diversa: sin negar el valor básico de la formulación lógica, quiere mostrar que, al formar parte de la tradición agustiniana, san Anselmo asume los términos de esa formulación con una comprensión distinta y más amplia que la que han asumido muchos de sus lectores. Nuestra aproximación quiere ir al fondo sustancial del argumento y a su verdad real, más allá de su forma lógica.

1 Artículo elaborado dentro del proyecto de investigación: "Conocimiento, Verdad y Razón: La tradición agustiniana en la Universidad”, financiado por la Universidad Francisco de Vitoria, 2019-2021.

2 Anselmo de Canterbury, Proslogion, en Obras completas: I (BAC, Madrid 2008) 351-405. La respuesta de Gaunilo y la réplica de Anselmo, en la misma edición: Gaunilo de Marmoutier, Quid ad haec respondeat quidam pro insipiente, 406-415 (en adelante: Pro insipiente); Anselmo De Canterbury, Quid ad haec respondeat editor ipsius libelli, 416-437 (en adelante: Quid ad haec).

3 Cf. D. Fuenmayor - Ch. Benzmüller, "Automating Emendations of the Ontological Argument in Intensional Higher-Order Modal Logic", en G. Kern-Isberner y otros (eds.), Advances in Artificial Intelligence. Lecture Notes in Computer Science, vol. 10505. Online, 19/IX/17: DOI: https://doi.org/10.1007/978-3-31967190-1_9 (consulta: 27/08/2020); Ch. BenZmüller - B. Woltzenlogel Paleo, "The Inconsistency in Gödel's Ontological Argument. A Success Story for AI in Metaphysics", Proceedings of the Twenty-Fifth International Joint Conference on Artificial Intelligence (AAAI Press, New York, 2016) 936-942. 
La forma lógica es la expresión material del argumento y por eso interesa mucho que la secuencia sea correcta. Pero para que el argumento sea verdadero, la corrección material es condición necesaria, no suficiente: se debe atender al sentido de los términos más allá de ellos mismos ${ }^{4}$. Ese sentido lo aporta el contexto de la tradición intelectual agustiniana a la que el texto pertenece. El núcleo del Argumento (Proslogion, 2-3), se puede destilar como sigue (dado que traducir "insipiens" como "insensato", "necio" o "ateo" añade connotaciones que no vemos en san Anselmo, mantendremos el término en latín):

1. El "insipiens" reconoce que "Dios" es "aquello-mayor-de-lo-cual-nada-puede-pensarse" (aliquid quo nihil maius cogitari potest).

2. El "insipiens" reconoce que "Dios" así definido existe en el intelecto del propio "insipiens".

3. El "insipiens" reconoce que existir "en el entendimiento y en la realidad" (in intellectu et in re) "es más/es mejor" (maius/melius) -i.e.: tiene un contenido y densidad mayor de realidad- que "existir solo en el intelecto".

4. En consecuencia, el "insipiens" tiene que reconocer que es contradictorio pensar que "Dios" es "aquello mayor/mejor de lo cual no puede pensarse nada" y al mismo tiempo pensar que "Dios" no existe.

5. Por tanto, "Dios" tiene que existir no solo "in intellectu" sino también "in re".

El corazón del argumento se encuentra en la aparente definición de Dios y lo que de ella se deduce: "Dios es aquello mayor de lo cual nada puede pensarse, por tanto existe" (Deus est aliquid quo nibil maius cogitari potest: ergo, est). Su fuerza está en la contradicción lógica y vital que el "insipiens" se ve obligado a reconocer, al admitir que comprende lo que el término Dios significa.

\section{INDiCIOS PARA UNA LECTURA AGUSTINIANA}

Los autores que rechazan el argumento dicen que no hay conexión necesaria entre el orden del pensamiento y el de la realidad. En la hi-

4 Cf. M. Heidegger, Kant y el problema de la Metafísica (CFE, México 1986) 289: "[...] lo que ha de ser decisivo en todo conocimiento filosófico no se encuentra en las proposiciones explícitas, sino en lo que estas presentan como algo implícito”. 
pótesis de que el argumento hubiera que entenderlo como ellos lo han interpretado, si todo se reduce a conectar sin más el plano ideal con el plano real, deberíamos preguntarnos por qué un experto en lógica como Anselmo no vio tal inconsecuencia. Y si las críticas fueran tan demoledoras como Kant quería, ¿por qué hay todavía autores que defienden el argumento?5 Pero, si lo damos como legítimo en el plano lógico, al constatar que los conversos a causa de su lógica formal son más bien pocos, habría que concluir que la eficacia del "argumento singular" (unum argumentum) que su autor veía como definitivo, es muy escasa, y su lógica se estrella con las razones del corazón humano... Entonces habría que preguntarse por qué un estudioso de la libertad humana y un místico como san Anselmo pudo pensar que bastaría un silogismo para que el "insipiens" reconociera la existencia de Dios. De modo que (tanto si aceptamos como si negamos la secuencia lógica del argumento), mientras nos quedemos solo en el plano del análisis lógico de sus términos, premisas y conclusiones, habrá que admitir que todo parece un mero divertimento especulativo.

Pero si la relación de la existencia de Dios con la existencia del hombre es el fondo del problema de Anselmo, entonces puede entenderse que no se trata de una discusión meramente abstracta, ni un juego lingüístico. Por el contrario, se trata de una cuestión vital, un problema que, mucho antes que al célebre "insipiens", afecta al propio Anselmo en primera persona, pues solo a partir de la existencia o inexistencia de Dios podrá comenzar a comprender el sentido de su propia existencia. Por eso es el fondo del problema el punto de vista desde el que afrontaremos nuestro estudio, no desde su forma lógica, sino desde la relación de la existencia de Dios con la existencia del hombre. Justo porque este es el problema crucial, importa atender al Argumento, tomar en serio a su autor y resolver con él la cuestión: ¿existe o no existe Dios? ¿Prueba o no la "ratio Anselmi" la existencia de Dios?

Una cosa es cierta: san Anselmo está convencido de que su razonamiento funciona ("lejos de duda" ${ }^{6}$, dice literalmente). ¿Cabe entonces

5 Cf. A. Plantinga, "Kant's Objection to the Ontological Argument", The Journal of Philosophy 63/19 (1966) 537-546. Vid. et.: W. Vallicella, "Does The Cosmological Argument Depend On The Ontological?", Faith and Philosophy: Journal of the Society of Christian Philosophers 17/4 (2000) 455.

6 Proslogion, 2. 
la posibilidad de que el Prior de Bec entendiera los términos de su argumento de modo, al menos en parte, distinto al de la lectura habitual (que llamaremos racionalista) desde Gaunilo hasta hoy? ¿Qué pasaría si lo hiciera? Para empezar, que esa lectura no tendría entonces necesariamente que ver, de modo directo y propio, con el pensamiento de Anselmo, al menos no con el pensamiento completo, sino solo con un sentido particular de su expresión formal. Habría que poner en entredicho la crítica negativa de algunos autores. Paralelamente, la confirmación del Argumento por parte de otros (de san Buenaventura a Plantinga) validaría la forma lógica, pero necesitaría todavía vincularse con el fondo del argumento para alcanzar su pleno sentido, y no quedarse en un silogismo verdadero en la lógica modal de los mundos posibles, pero inútil para mover el corazón.

Por supuesto, no es esta la primera vez que algo así se plantea: Julián Marías ${ }^{7}$ sugirió una lectura distinta de la racionalista en un ensayo de juventud; y en Teología es luminoso el estudio de von Balthasar ${ }^{8}$ y la traslación que hace a la relación de amor del cristiano y su Maestro?. Malcolm ${ }^{10}$ intuye la necesidad de ir a la cuestión religiosa en su famosa reivindicación del argumento, pero solo apunta a ello en la conclusión. Seifert sí la afronta, a través de la versión del argumento que da san Buenaventura ${ }^{11}$. De modo sugerente, Marion rechaza el carácter ontológico del argumento (en la comprensión kantiana-heideggeriana del término) y enmarca el Proslogion en su tradición agustiniana ${ }^{12}$. Más recientemente, parecen ir en esta dirección autores como Pruss ${ }^{13}$ que vincula su for-

7 Cf. J. Marías, "San Anselmo y el insensato y otros estudios de filosofía” (Revista de Occidente, Madrid 1944).

8 Cf. H. U. von Balthasar, Gloria, II: Formas de estilo: I: Estilos eclesiásticos (Encuentro, Madrid 1986).

9 Cf. H. U. von Balthasar, Seriedad con las cosas. Córdula o el caso auténtico (Sígueme, Salamanca 1969) 49 y 87.

10 Cf. N. Malcolm, "Anselm's Ontological Arguments", The Philosophical Review 69/1 (1960) 61.

11 Cf. J. Seifert, "Si Deus Est Deus, Deus Est. Reflections on St. Bonaventure's Interpretation of St. Anselm's Ontological Argument”, Franciscan Studies 52 (1992) 215-231.

12 Cf. J.-L. Marion, "Is the Ontological Argument Ontological? The Argument According to Anselm and Its Metaphysical Interpretation According to Kant", Journal of the History of Philosophy 30/2 (1992) 201-218.

13 Cf. A. R. Pruss, "The ontological argument and the motivational centres of lives", Religious Studies 46 (2010) 223-249. 
ma lógica con los "centros motivacionales de la vida", o el padre André Hubert, que ha evidenciado la relevancia del amor en toda la obra de Anselmo y lee el Argumento en horizonte escatológico ${ }^{14}$. ¿Cuál sería la base para una lectura diferente de la racionalista? ¿Cómo podríamos saber que él entendió su argumento en otras categorías y los términos con otra comprensión, si no fue en el sentido de la lectura racionalista? Partimos de la sugerencia de Marías: atender a la comprensión del texto en su contexto ${ }^{15}$.

Es obvio que san Anselmo no es un moderno, ni un fenomenólogo, ni un kantiano. En sus escritos ${ }^{16}$ muestra que no es ni siquiera un dialéctico de los que ya en su época existían, preocupados más de los significantes que de los significados. Es un monje benedictino medieval de tradición intelectual agustiniana: un cristiano que busca comprender su fe para poder vivirla, como dice expresamente en el proemio. En su mundo hay -todavía, a pesar de Roscelino- una conexión natural entre ideas y realidad: las ideas no son solo (ni principalmente) contenidos de conciencia sino antes y siempre signos eficaces en los que se nos hace presente la realidad ${ }^{17}$. Anselmo pertenece, a través de Agustín, a la posteridad filosófica de Platón ${ }^{18}$. Por todo ello, no puede admitir que Dios exista antes en el entendimiento que en la realidad. Al revés: se nos muestra convencido de que el ser de las criaturas depende y participa del ser divino ${ }^{19}$.

14 Cf. A. Hubert, "El enigma del hombre según san Anselmo", Teología y Vida 45/4 (2004) 494-530. https://scielo.conicyt.cl/scielo.php?pid=S004934492004000400002\&script=sci_arttext (consulta: 27/08/2020).

15 Cf. J. Marías, san Anselmo y el insensato, 6-7.

16 Cf. Proslogion, 4, y Quid ad haec, II y V, donde se ve el rechazo que hace del nominalismo que detecta en Gaunilo. Vid. et. De Veritate, II, en ANSELmo DE CANTERBURY, Obras completas: I, 546.

17 Cf. De Veritate, 2, 7 y 10. Véase: H. U. von Balthasar, Gloria, II, 228: “[...] en la gnoseología de Anselmo toda afirmación de esencia es función de una afirmación de la existencia. Si la función de signo y significado puede considerarse y comprenderse por sí, prescindiendo de su contenido existencial adecuado, es porque se la considera siempre en referencia a su aplicabilidad a lo real". Cf. G. STEINER, Presencias reales (Destino, Barcelona 2007) 253.

18 Cf. J.-L. Marion, "Is the Ontological...?” 201-218.

19 Cf. De Veritate, VII. 
Tras la estela del obispo de Hipona ${ }^{20}$, san Anselmo vive en una era que concibe todavía la Filosofía como amor a la Sabiduría, en la que el conocimiento aportado por la Revelación y la fe es la respuesta por parte de Dios a la búsqueda de la razón natural ${ }^{21}$. No hay ruptura en san Anselmo -ni en san Agustín- entre Filosofía y Teología, sino que esta es la coronación de aquella. Esto implica que lo que se busca conocer y se conoce por iluminación de la Verdad se traduce en la propia experiencia viva del hombre: la Sabiduría es para la vida ${ }^{22}$. Es cierto que en su tiempo el nominalismo había comenzado a separar los dos ámbitos (razón/ fe, filosofía/teología, naturaleza/gracia), lo que lleva o bien a disolver uno de esos polos en el otro, o a considerar al contrario como superfluo y digno de ser eliminado. De allí arrancan dos modos de pensar radicalmente modernos: fideísmo y racionalismo, y su dialéctica irreconciliable. Anselmo combate esta dialéctica: con "razones necesarias" que muestran la integración armónica de fe y razón, defiende la fe frente a los racionalistas y la razón frente a los fideístas ${ }^{23}$.

Un indicio de que Anselmo se mueve en ese plano de Sabiduría vital se ve en la manera de responder a Gaunilo. Le pide que deje de considerar los términos en su aspecto meramente material, como datos desligados de toda otra realidad, que se eleve y descubra que son signos de una realidad significada que va más allá de ellos a la que están naturalmente vinculados y que, de algún modo, se hace presente en ellos. Si esto es intencionalmente así de los términos que se refieren a las realidades de las que tenemos experiencia directa (seres contingentes), si ya en las mismas palabras -e ideas- de las cosas creadas se nos dan "presencias reales" 24 , ¿cuánto más no va a ser ello posible en Aquel Existente cuya existencia posibilita todas las demás?25.

Comprender el contexto de Anselmo nos hace ver que la pregunta a la que quiere responder es la del drama de toda vida humana, también la

20 Cf. Agustín de Hipona, De Civitate Dei, VIII, 1, en Obras completas, XVI (BAC, Madrid 2000); y De Trinitate, XII, 14, en Obras completas, V(BAC, Madrid 2006).

21 Cf. Proslogion, 1.

22 Cf. Agustín de Hipona, De Trinitate, XII: 15, 25.

23 Cf. el contraste entre el Monologium y la Epistola de Incarnatione Verbi. Ambas en la edición citada, 183-347 y 681-735, respectivamente. Cf. M. BЕAUCHOt, "El argumento 'ontológico' de san Anselmo”, Medievalia 15 (1993) 30.

24 Cf. G. Steiner, Presencias reales, 236-242.

25 Cf. J. Seifert, “Si Deus Est Deus”, 224-225. 
suya: la búsqueda de Dios. Basta con leer el proemio y el primer capítulo y asumir la sinceridad de su planteamiento para darse cuenta de que de lo que trata todo el Argumento es de la radical necesidad que tiene el propio Anselmo -y todo hombre- de "buscar el Rostro de Dios" él mismo y para él mismo. ¿Cómo puede nadie que haya leído el capítulo primero decir que Anselmo quiere demostrar que Dios es evidente para todos, cuando el Prior constata, con dolor y amargura, que "no lo ha visto nunca" ${ }^{26}$ ?

Sin embargo, al mismo tiempo reconoce que no puede dejar de buscar Su Rostro ${ }^{27}$. Nos señala así la urgencia vital que tiene de encontrar a Dios y, con Él, el sentido de su propia existencia. El libro comienza y concluye con sendas oraciones -aunque el tono de una y otra sea tan distinto como el que va del deseo inquieto a la paz del encuentro ${ }^{28}$ - y a lo largo de todo él, el autor dialoga con el Dios al que busca. La oración inicial pide comprender las implicaciones de la idea objetiva y real de Dios: "inteligir tu verdad" (intelligere veritatem tuam) ${ }^{29}$. De esta forma tan agustiniana muestra que su camino no es un recorrido solitario, sino que de alguna manera puede "buscar porque antes ha sido encontrado", porque en su corazón Dios ha puesto la inquietud esperanzada de esa búsqueda ${ }^{30}$. El Proslogion entero se mueve en el contexto de la filosofía agustiniana de la inquietud, del diálogo, de una razón abierta. Se ve así que el punto de partida de Anselmo no es, sin más, la fe (no desde luego en sentido fideísta), sino el "existir" (esse) de la condición humana: cuando en el primer capítulo nos revela su corazón inquieto, también nos habla de la "memoria" que es nuestra identidad ${ }^{31}$. Esa memoria es deseo de belleza, verdad y bien: deseo de Dios. Tal deseo no es un dato que Anselmo conozca por fe, sino un dato universal del hombre, también de quien no tiene $\mathrm{fe}^{32}$. Anselmo parte del esse, de la existencia dramática, porque siente en su propia carne la nostalgia de Dios $-\mathrm{y}$ hablar de nos-

Proslogion, 1 y 26.

Proslogion, 1

Proslogion, 25-26.

Proslogion, 1. Véase también: J. Seifert, “Si Deus Est Deus", 222.

30 Cf. Agustín de Hipona, De Trinitate, X, 11, 18, y Confessiones X, en Obras completas, II (BAC, Madrid 1981).

31 Cf. Agustín de Hipona, Confessiones, I, 1. Anselmo de Canterbury, De grammatico, 19; Cur Deus homo: praef.

32 Cf. G. K. Chesterton, The Thing, 31, en Collected Works of. G.K. Chesterton, III (Ignatius, San Francisco 1990) 312. 
talgia en un hombre cuya existencia es memoria, es confesar que buscamos algo que aparentemente no hemos visto y sin embargo podríamos reconocerlo en cuanto lo viéramos ${ }^{33}-$.

El texto tiene, además, expresiones elocuentes en relación con un fondo que va mucho más allá de una simple coherencia lógica: La formulación en negativo del Argumento es indicio del carácter limitado de nuestro conocimiento, ya que ninguna idea nuestra podrá nunca contener a Dios. Así, cualquier definición -o sea, delimitación- que demos de Él tiene que ser más bien de lo que no es Dios: Dios no es aquello que puedo pensar como lo máximo, sino más bien Dios es mayor de lo máximo que puedo pensar - mayor también con el sentido de mejor: Marion se detiene oportunamente en los términos para mostrar el carácter inaprensible de la realidad divina y su irreductibilidad a un concepto; así, junto con la expresión en negativo, señala también el comparativo (maius) y su comprensión (platónico-agustiniana) como melius ${ }^{34}-$. El uso del comparativo en lugar del superlativo es signo de una sutil precisión y delicadeza al definir sin definir a Dios. Dios no es un concepto que quepa en una definición o en nuestro entendimiento -no lo era ni siquiera en el sentido antiguo de idea, mucho menos en el sentido racionalista moderno ${ }^{35}-$.

Esto es algo que ciertos críticos de san Anselmo no alcanzan a ver: en su misma formulación el Prior rechaza que Dios pueda ser constreñido a un mero objeto mental del hombre (es explícito en los capítulos 1 y 15). Casi inevitablemente, aquellos críticos tienden a comprender la idea de Dios como una idea subjetiva; Seifert y Plantinga han hecho ver, por ejemplo, que esto está en la base de la crítica kantiana al argumento y han mostrado que, precisamente por eso, la crítica no es justa ${ }^{36}$. La formulación en pasiva (cogitari), en negativo (non posse) y en comparativo" (magis/melius), sugiere con toda claridad las vías "negativa”, "apofática” y "de eminencia” de los místicos. En su definición no nos dice qué es Dios, sino qué no es Dios: desde luego no es la pobre, débil idea que un hom-

33 Proslogion, 2. Cf. Monologion, 1 y 68, donde alude al "desiderium naturale" en relación con el fin del hombre.

34 Cf. J.-L. MARION, "Is the Ontological...?" 201-218. Véase también: Quid ad haec, 8-9.

35 Cf. H. U. von Balthasar, Gloria, II: 227. Véase también: J. Seifert, "Si Deus Est Deus", 228.

36 Cf. J. Seifert, “Si Deus Est Deus", 230. Véase también: A. Plantinga, "Kant's Objection...", 545-546. 
brecillo ("homuncio") pueda tener; Dios no es mi idea de Dios, subjetiva, prejuzgada y proyectiva, por muy elevada que esta pudiera ser; Dios está infinitamente por encima de ella y precisamente por eso no hay ninguna idea que yo pueda formar que sea, si es verdadera, mayor que la idea de Dios. Lo más que puedo hacer es pensarlo con una idea al negativo y en comparativo de siempre más -Dios no es mi idea, sino algo más grande que la idea más grande que pueda yo pensar-. San Anselmo piensa a Dios con una idea puesta del revés y elevada al infinito y lo llama con un término que (también lo sabe) no es un nombre adecuado, sino solo un "nomen/signum" para poder referirnos de algún modo a ese Existente tan totalmente Otro. Entendida con estas salvedades, la expresión de Anselmo designa entonces a un Existente que es la máxima entidad, un Existente máximamente existente, la "Summa Essentia". Por eso no podemos hacernos una idea exacta de ese existir, aunque sí verdadera: pensar a Dios como existente, es pensarlo como de algún modo es en sí mismo ${ }^{37}$.

Otra expresión significativa es el verso del que parte para su reflexión: "Dice el necio en su interior: ¡No existe Dios!" (Sal 14 [13] 1: Dixit insipiens in corde suo: non est Deus). No es una cita bíblica accidental, ya que hay otros lugares en el texto sacro para referirse a los que rechazan a Dios (pecadores, ignorantes, paganos, malvados), o lugares con argumentación, digamos atea, más sólida (p. ej., Eclesiastés o Job). Más que recurso literario o expresión filosófica, es la declaración desolada del corazón del hombre al que el mal le impide ver a Dios por ningún lado. Por eso, cuando Anselmo dice que el "insipiens" niega a Dios “in corde suo", apunta a que ni la negación de Dios ni su afirmación pueden darse solo en el plano lógico, sino que envuelven a la persona totalmente desde sus entrañas hasta el último de sus actos. El amor y el rechazo de Dios son asuntos que se dan en el centro íntimo de la persona (in corde suo, ex toto corde). Y como ya explicó san Agustín ${ }^{38}$, el rechazo solo puede darse si el amor de Dios es sustituido por otro amor: un ídolo que se adora como si fuera Dios.

Precisamente porque es un argumento "in corde suo", resulta inadecuado llamarlo "a priori" y "ontológico", pues arranca de la experiencia del corazón, y no de un concepto puro de Dios que Anselmo no tiene

37 Cf. J. Seifert, "Si Deus Est Deus", 224-225.

38 Cf. Agustín de Hipona, De Civitate Dei, XIV, 28. 
-lo que tiene es un "no-concepto" (no-concept) $)^{39}$-. Parte además de la $\mathrm{fe}^{40}$, que supone una cierta experiencia de relación entre el sujeto y una alteridad distinta a él, y Marion ha mostrado la implicación racional que esto tiene en el argumento ${ }^{41}$. Anselmo trata con Dios, aunque no sepa bien quién y cómo es. Ha experimentado un cierto encuentro, por más que lo exprese con los rasgos de la nostalgia, la ausencia, el deseo (el primer capítulo parece el reverso del encuentro con Dios descrito por san Agustín en las Confessiones ${ }^{42}$ ). Además, entender a Dios como máximamente existente es descubrirlo como fundamento de mi existencia contingente y por eso el argumento es "a simultaneo" 43 .

Detengámonos en la significación de un término que, a primera vista, no parece contener toda la densidad que -creemos-Anselmo quiere darle. Ese término es "cogitari". La tradición posterior lo ha comprendido casi siempre simplemente como pensar, en el sentido de tener un pensamiento-contenido-mental o concepto. Así lo entendió Gaunilo: lo dice expresamente en su defensa del "insipiens" ${ }^{44}$. Y parece que así lo entendieron después casi todos, a pesar de que al responder a Gaunilo, Anselmo repita con paciencia benedictina una distinción que había antes hecho en el propio Proslogion ${ }^{45}$.

No se trata únicamente de la distinción de "lo que existe solo en el intelecto" frente a "lo que existe en el intelecto y en la realidad" sino a dos modos de "existir en el intelecto" 46 , uno que podemos llamar inadecuado y otro adecuado: el primero es comprender la idea como una simple impresión mental, como un dato arbitrario, cerrado en sí mismo, sin referencia a nada más que él, o, a lo sumo, con una referencia convencional y arbitraria a otra cosa. Y lo que vale para ese signo que es la idea vale también para su expresión verbal, que, en este caso, solo sería el ruido

39 Cf. J.-L. Marion, "Is the Ontological...?” 201-218. Véase también: G.E.M. AnsCombe, "Why Anselm's Proof in the Proslogion is not an Ontological Argument", Thoreau Quarterly 17/1-2 (1985) 32-40.

40 Cf. Proslogion, 2 y también la respuesta a Gaunilo: Quid ad haec, 1.

41 Cf. J.-L. Marion, "Is the Ontological...?", 201-218.

42 Cf. Agustín de Hipona, Confessiones, X, 27, 38.

43 Cf. N. Tovagliari, Pensare l'Impensabile. La validità e la fortuna dell'argomento di Anselmo sull'esistenza di Dio (APRA, Roma 2011) 13.

44 Cf. Gaunilo de Marmoutier, Pro insipiente, 2.

45 Cf. Anselmo de Canterbury, Quid ad haec, 4 y Proslogion, 4.

46 Cf. Proslogion, 2-4. 
de unos sonidos. Pero este modo de "estar en el intelecto" es estéril: no produce ningún conocimiento, ni de la realidad de Dios, ni de ninguna realidad contingente. No por nada quienes han entendido las ideas y palabras en este sentido terminan creyendo, afirmando y enseñando que nunca alcanzamos la realidad, que a penas rozamos los fenómenos de las cosas, nunca los "noumena", que solo "nomina nuda tenemus"-ni siquiera eso, pues solo somos "un haz o colección de percepciones" (a bundle or collection of different perceptions $)^{47}-$.

El Prior de Bec sabe que algunos entienden así las ideas -Roscelino-y por lo mismo rechaza que ese modo de existir en el intelecto sea el modo al que él, Anselmo, se ha referido. Por eso lo distingue de otro modo de existir en el intelecto: una idea está adecuada y verdaderamente en el intelecto cuando se la ha comprendido, cuando se ha visto la conexión necesaria que hay entre esa idea y la realidad de la cual es signo. O sea: cuando tal idea ha sido iluminada en su Verdad, cuando es verdadera. Ser verdadera no siempre significa exactamente lo mismo que existir fuera de la mente sino estar en "rectitud" (rectitudo) y concordancia con su propio modo de existir ${ }^{48}$ : La idea de pegaso es verdadera no porque el intelecto vea que existe fuera de él "in re" sino precisamente porque ve que no existe más que en el intelecto: allí alcanza esa idea su verdad (y algo análogo podría decirse de la isla perdida de Gaunilo y de los cien táleros de Kant). Entendida así, la idea de un Existente máximamente existente solo podría alcanzar su verdad -solo sería adecuada- si tal Existente existiera: si su existencia es lógica y ontológicamente necesaria. Pero en esto estamos todavía en el ámbito de la lógica formal y creemos que Anselmo en la expresión lógica quiere ir mucho más allá de la expresión lógica.

Este segundo modo, adecuado, propio y verdadero, de "existir en el entendimiento" no es comparable con el primero, de tipo nominalista. Pero tampoco es exactamente un modo de tener ideas "claras y distintas" en la razón que puedan guardar relación con la "res extensa": No es un modo racionalista de entender las ideas. Por el contrario, "existir en el entendimiento" es para Anselmo tener las ideas en la armonía del "existir-conocer-amar" (esse-videre-amare) propia de la tradición agus-

47 Cf. D. Hume, A Treatise of Human Nature: I, IV, VI (Clarendon, Oxford 1896) 134. https://people.rit.edu/wlrgsh/HumeTreatise.pdf (consulta: 27/8/2020).

48 Cf. Anselmo de Canterbury, De Veritate, 2, 7 y 13. 
tiniana ${ }^{49}$ en la que él se encuentra y que manifiesta desde el principio hasta el final del Proslogion ${ }^{50}$. De esta forma, "cogitari" -y en activa: "cogitare"- no es, sin más, tener razones y conectarlas con la realidad. "Cogitari" tiene una valencia parecida a "illuminari" ${ }^{51}$ y por tanto está en relación con estar-inmerso en un "esse" cuya luz me permite "videre" 52 y ello me mueve a "diligerelamare" 53 , ya que la inquietud del corazón está presente en ese cogitari. Como en las procesiones trinitarias que son su fundamento, en la metafísica agustiniana y anselmiana, existirconocer-amar están tan íntimamente relacionados que no se los puede separar, ya que uno implica los otros dos aspectos ${ }^{54}$. Lo había explicitado con toda rotundidad el Prior de Bec en el Monologion ${ }^{55}$. Más aún: si se los intenta separar, se pierden los otros dos aspectos y aquel que pretendemos retener queda tan falsificado que nos resulta inútil para alcanzar lo que buscábamos -que no era "tener ideas claras y distintas" sino llegar a la Sabiduría ${ }^{56}$.

Por eso, "ver" que "Dios es aquello mayor de lo cual nada puede pensarse" implica una conciencia a simultaneo de la propia existencia en relación (ontológica y de amor) con la existencia de Dios. Cuando el entendimiento "comprende" -es decir: está situado en una realidad que ve y que también ama- que Dios es aquello mayor de lo cual no puede pensarse nada, entonces no solo entiende que "Dios existe", sino que también se entiende a sí mismo como existente en una relación de

49 Cf. Agustín de Hipona, De Trinitate, XIV: 6, 8; De Civitate Dei, XI, 24.

50 Cf. Proslogion, 1, 26.

51 Cf. Agustín de Hipona, De Magistro, XII, 40, en Obras completas, III (BAC, Madrid 2009).

52 Cf. Agustín de Hipona, Soliloquiorum, I, 7-8, en Obras completas, I (BAC, Madrid 1994).

53 Cf. Agustín de Hipona, Soliloquiorum, I, 13-14; De Trinitate, XV: 6, 10.

54 "Es evidente que el amor es consecuencia lógica de la memoria y de la inteligencia". A. Hubert, "El espíritu humano y la dramaticidad de su trascendencia según el Monologion de san Anselmo". Teología y Vida 56/4 (2015) 379-405. https://scielo.conicyt.cl/scielo.php?pid=S0049-34492015000400002\&script=sci_arttext\&tlng=n (consulta: 27/8/2020).

55 "Nam si mens ipsa sola ex omnibus quae facta sunt, sui memor et intelligens et amans esse potest: non video cur negetur esse in illa vera imago illius essentiae, quae per sui memoriam, et intelligentiam, et amorem in trinitate ineffabili consistit. Aut certe inde verius esse illius se probat imaginem, quia illius potest esse memor, illam intelligere et amare" (Monologion), 67.

56 Cf. H. U. von Balthasar, Gloria, II, 214. 
dependencia ontológica y amorosa respecto de "aquello mayor de lo cual no puede pensarse nada" ${ }^{\prime \prime}$.

Para san Anselmo y la tradición agustiniana, hay una triangulación necesaria entre existir-conocer-amar ${ }^{58}$ : los tres se implican mutuamente $\mathrm{y}$, aunque pueden distinguirse, no se da uno sin el otro, sino que el uno lleva a los otros dos y viceversa: se ama lo que se conoce, se conoce lo que es; pero solo se conoce lo que verdaderamente se ama y solo el amor nos lleva a la plenitud de la existencia. Por eso "esse in intellectu" es también "esse in corde". Y cuando el "insipiens" dice "no hay Dios" no lo dice solo con su razón, sino "in corde suo", como una vivencia real propia, no como una deducción lógica. De hecho, la fuerza del argumento está en que una verdadera deducción lógica (y como verdadera no solo lógica, sino dramáticamente vital) llevaría al "insipiens" a la conclusión contraria a la que sostiene. Por la vivencia que el argumento implica, la pura lógica materialmente correcta es insuficiente para la conversión: el corazón del "insipiens" tiene las profundas razones de su propia experiencia. Anselmo no dice cuáles sean tales razones, pero las sugiere el Salmo que cita para dar voz al "insipiens": tiene embotado el entendimiento porque antes tiene enfermo el corazón.

Por eso, la cuestión de fondo de todo el argumento anselmiano es una cuestión vital, no una cuestión lógica. La forma lógica solo es la expresión material que Anselmo usa para mostrar las "rationes necessariae" sustanciales para solucionar el problema. Pero el problema es un problema vital: Si Dios no existe, ¿qué sentido tiene mi propia existencia ${ }^{59}$ ? Si no hay un Existente eterno, si no hay una última causa que funda sólidamente el existente que soy yo, ¿qué puede hacer estable y duradera mi frágil existencia? Y si solo un Existente máximamente existente puede garantizar la supervivencia de mi propio yo, entonces, ¿cómo puedo saber con verdad que Dios existe (y no solo con "certeza subjetiva")? Solo si me doy cuenta de que entre Él y yo hay una relación de existencia-conocimiento-amor, solo si descubro la ratio necessaria entre su Esse-Videre-Amare y el mío, podré estar seguro en la verdad -defi-

57 Cf. G. Steiner, Presencias reales, 13-14. Véase también: M. eliade, Historia de las creencias y las ideas religiosas: I (Paidós, Barcelona 1978) 17.

58 Cf. H. U. von Balthasar, Gloria, II, 213.

59 Cf. N. Malcolm, "Anselm's Ontological Arguments", 62. 
nida como "rectitudo" porque establece la línea continua y firme entre existir-entender-actuar ${ }^{60}-$.

\section{REFORMULACIÓN Y CONSISTENCIA DEL ARGUMENTO ANSELMIANO}

Newman -también agustiniano- distingue dos formas de "aprehensión o interpretación", que llama "nocional" (notional) y "real" (real) ${ }^{61}$. Con esto diferencia dos tipos de conocimiento y de pensamientos: los primeros son precisos, exactos hasta traducirse en fórmulas universales y los valoramos por los efectos prácticos que tienen, pero no tocan el centro de nuestra existencia; los segundos, aunque sean borrosos, difíciles de definir o expresar, llegan al corazón de nuestra vida, a su núcleo más íntimo, hasta justificarla y darle sentido. La distinción es parecida a la de Anselmo cuando recuerda a Gaunilo que una idea puede estar de dos modos "in intellectu": Uno es como simple dato; otro es comprendiéndola a fondo. Pero la distinción es más profunda y Seifert advierte que, sobre esa base, san Buenaventura había diferenciado entre "pensamiento desnudo" (cogitatio nuda) y "pensamiento con asentimiento" (cogitatio cum assensu) ${ }^{62}$. von Balthasar señala que ya en el Monologion, Anselmo discierne cuatro modos de conocer $\operatorname{algo}^{63}$. Más recientemente, Pruss habla de una "semántica de dos dimensiones" que puede "mejorar el argumento ontológico" y así distingue entre "creencias periféricas" y "centrales" (peripheral/central beliefs) 64.

60 Cf. De Veritate, II y V; J. Seifert, "Si Deus Est Deus", 218.

61 Cf. J. H. Newman, An Essay in Aid of a Grammar of Assent (London 1903) I, 1: 2: http:// www.newmanreader.org/works/grammar/chapter1.html (consulta: 27/8/2020).

62 Cf. J. Seifert, "Si Deus Est Deus", 230. Véase también Buenaventura de Bagnoregio, Quaestiones disputatae de Mysterio Trinitatis, q. 1, a. 1. http://www.archive.org/stream/ doctorisseraphic05bona\#page/50/mode/1 up (consulta: 27/8/2020).

63 "Pensar no es propiamente jugar con los conceptos, ni mirar a imágenes. Monologion 10 enumera cuatro grados: 1) la simple mención indicativa de un nombre significativo, como "hombre"; 2) la cogitación interior del hombre (nomen cogitare); 3) la visión espiritual de la cosa mediante una imagen sensible (imago); 4) la visión espiritual de la cosa mediante la ratio. Mientras la imago representa solo la figura sensibilis, la razón capta la universalis essentia. Proslogion 4 distingue una vez más el segundo grado y el cuarto [...] Pero estos grados, referidos a la obra salvífica divina, no miran a la cosa, sino a su mayor o menor acogida por el sujeto" (H. U. vON Balthasar, Gloria, II), 221-223.

64 Cf. A. R. Pruss, “The ontological argument and...” 234-235. 
En el lenguaje agustiniano de Anselmo, "cogitare" está emparentado con intelligere, cognoscere, nosse, y muy especialmente con videre, con toda la densidad que estos términos tienen para esa tradición. Como ha evidenciado von Balthasar ${ }^{65}$, hay una relación natural e intrínseca entre estos verbos de conocimiento con los verbos de las otras dos dimensiones del "ordo amoris": existir-amar. Más aún: en analogía con el HijoLogos en la Trinidad, la mediación del "videre/cogitare" es central entre las dimensiones de la existencia y la libertad, de donde resulta también central para nosotros por la Encarnación ${ }^{66}$. Por eso, el Teólogo suizo destaca acertadamente la "razón estética" de Anselmo, una razón que reorienta el pensamiento a "la visión de conjunto, la capacidad de retomar y conjuntar, que es el sentido primitivo de legere, logos", una razón que conduce y desemboca en el "deleite, gaudium, delectatio [...] ante la 'altísima belleza' de Dios" ${ }^{37}$.

Si esto es así, cuando san Anselmo explica que Dios es "aliquid quo nibil maius cogitari potest", lo que parece querer significar es que Dios es "aquello mayor de lo cual no puede existir-pensarse-amarse nada". En consecuencia, resulta lógica y vitalmente contradictorio suponer que Dios no exista: es absurdo, imposible. Porque para Anselmo, "cogitare" no es tener contenidos de conciencia sino comprender la realidad; "intelligere" no es conectar conceptos abstractos sino llegar a lo real; "cogitatio" no es un dato intra-mental sino la vinculación necesaria con la realidad; “intellectus" no es nunca el espacio cerrado, autónomo, autoproyectado, autoconsciente, autosuficiente, sino la capacidad para acce-

65 "Videre es término fundamental por entender (Verstehen) y es regularmente el resultado de una indicación (Aufweis), que por su claridad y su simplicidad tiene algo de irrefutable, de evidente [...]. Este video continuamente se aplica también a la dificultad [...]. Da al videtur mihi un matiz eidético peculiarísimo [...] A videre puede remplazar cualquier verbo activo con significado visual: intuiri (Mon. 49, 62), cogitando intuiri (Mon. 63), inspicere (De ver. 5), speculari (Mon. 6, clara alusión a la visión por espejo), contemplari (De ver. 5) del que se pasa sin discontinuidad a considerare y a meditari. Muchas veces se habla de la transparencia de la verdad: liquida vera [...]. Afloran constantemente los términos aperire (De cas. diab. 26), apertum (Mon. 7), ratio aperta (De gramm. 19, Cur Deus homo praef., De conc. III: 6, Medit. III), apertissime probare (Cur Deus homo II: 14). Esta apertura a la verdad y de sus razones hace aparecer la verdad irrefutablemente: inexpugnabiliter (Mon. 29), ratio (o necessitas) inevitabilis (Mon. 22), irrefrangibilis (De proc. Spir. 1) indubitabilis (Mon. 54)" (H. U. von Balthasar, Gloria, II), 217-220.

67 Cf. H. U. von Balthasar, Gloria, II, 222; 229. 
der a lo real: es la capacidad de trascendencia, de salir de mí y entender (literalmente tender-hacia) lo que hay fuera de mí y relacionarme con ello; "intellectus" - "intus-legere”- es así algo diametralmente opuesto al "cogito" cartesiano, la razón pura kantiana, o la conciencia de los fenomenólogos idealistas... Es la transparencia hacia lo real, la proyección a la vida, su amor y, por eso mismo, también su gozo ${ }^{68}$. Estos términos incluyen, en Anselmo y en la tradición de la que beben, un aspecto cordial que obliga a comprenderlos en relación con el amor: esse-videre-amare ${ }^{69}$. Así, "pensar/conocer" es también "querer/amar/elegir". Y porque "intellectus" es también "cor", "conocer" a Dios es "elegirlo" -por eso, como von Balthasar y Marías subrayan, Anselmo habla de "creer hacia Dios" (credere in Deum), en tensión de amor creciente ${ }^{70}$.

Por tanto, cuando San Anselmo refiere que el “insipiens" dice en su corazón "Non est Deus", nos da a entender que el "insipiens" puede pensar a "Dios" en dos planos: o como un nombre sin sentido -y entonces en realidad no está "pensando" a "Dios"- o bien lo está pensando como "razón última de su propia vida" -y entonces tiene que concluir que necesariamente existe, pues de otro modo, es la propia existencia del "insipiens" la que carece de sentido-: Si no existe una razón última que justifique su vida y que tal razón sea máximamente existente, el “insipiens" tiene que carecer entonces de ella.

Podría objetarse que si el Prior de Bec hubiera querido decir que "cogitare/intelligere" debe entenderse en relación con la tríada agustiniana "esse-videre-amare", lo habría dicho de modo explícito (y más si hay que leer "cogitare" en continuidad con "diligere"). Frente a esa objeción, lo que planteamos no pasaría de ser una mera conjetura, si tuviéramos en cuenta únicamente la formulación escueta de los capítulos 2 y 3 del Proslogion, pues allí, a tenor de la literalidad de las palabras, solo se habla, explícitamente, de "cogitari". Pero no es lícito aislar esos dos capítulos del resto de la obra, sino que hay que leerlos en conexión con toda ella. Así, en Proslogion 1 se ve que todas las expresiones con que Anselmo se

68 Cf. H. U. von Balthasar, Gloria, II, 217, 228, 229.

69 Cf. H. U. von Balthasar, Gloria, II, 221, 223.

70 Cf. H. U. von Balthasar, Gloria, II, 226; Marías, J., San Anselmo y el insensato, 11-12; Monologion, 75. Todo el trasfondo es San Agustín, Cf.: Enarrationes in Psalmos, 77, 8; 130, 1; 144, 2; In Evangelium Ioannis Tractatus, 29, 6; 48, 3, citado en E. Teselle, "Faith", en A. D. Fitzgerald (ed.). Augustine through the Ages (Eerdmans, Grand Rapids - Cambridge 1999) 349. 
refiere a lo que podemos designar como "búsqueda intelectual de Dios", van acompañadas de términos que aluden a una inquietud cordial, amorosa, de necesidad vital ${ }^{71}$, hasta desembocar en una reformulación de expresiones agustinianas que conjugan conocimiento y amor de modo tan indisoluble, que aparecen como recíprocamente convertibles: "deseo entender tu verdad, la cual cree y ama mi corazón"72.

Se evidencia allí la profunda conexión y respectividad mutua que Anselmo ve entre "intellectus" y "cor", entre pensar y amar. "Quaerere, quaerens" son términos que refiere por igual tanto a la investigación teórica (inquisitio, quaestio) como a la búsqueda inquieta del corazón amante (no de otro verbo viene en castellano querer con el sentido de amar). Por eso, hay un paso fluido, natural, recíproco, entre "memor [sim], cogitem, amem". Por eso la intención del intelecto de "penetrare altitudinem [...] intelligere veritatem" se da en función y dependencia de un corazón que "desiderat, credit, amat". Precisamente por eso, el famoso "intellegere ut credam" de san Anselmo se aparta del racionalismo posterior y se inscribe en el conocimiento amoroso del entendimiento "caritate informatus" (como la fe y con ella).

También en los capítulos posteriores al tercero se ve la respectividad mutua entre existir-conocer- $\operatorname{amar}^{73}$, y las consecuencias del Argumento se traducen a la dimensión cordial-vital de la persona -es clamoroso al

71 "tumultuosis cogitationibus"; "totum cor meum, [...] quaero vultum tuum”; "doce cor meum"; "quaeram absentem [...] non video praesentem"; "lucem inaccesibilem [...] ducet et inducet in illam ut videam"; "non novi faciem tuam"; "anxius amore"; "Anhelat videre te et nimis abest illi facies tua. Accedere ad te desiderat, et inaccesibilis est habitatio tua. Invenire te cupit, et nescit locum tuum. Quaerere te affectat, et ignorat vultum tuum"; "nondum novi te"; "Volebam ridere a gaudio mentis meae, et cogor rugire a gemitu cordis mei"; etc. (Proslogion), 1.

72 "Quaeram Te desiderando, desiderem quaerendo, inveniam amando, amem inveniendo. [...] creasti in me hanc imaginem tuam, ut Tui memor Te cogitem, Te amem. [...] Non tento Domine, penetrare altitudinem tuam, quia nullatenus comparo illi intellectum meum; sed desidero aliquatenus intelligere veritatem tuam quam credit et amat cor meum. Neque enim quaero intelligere ut credam, sed credo ut intelligam. Nam et hoc credo: quia nisi credidero, non intelligam" (Proslogion), 1.

73 Por ejemplo, en la fluidez y correspondencia entre sensibilidad e inteligencia: "Non inconvenienter dicitur aliquo modo sentire, quidquid aliquo modo cognoscit". O en la "inteligencia del corazón": "Quid es, quid Te intelliget cor meum?”. O la conexión entre existencia y pensamiento: "An etiam quia illa cogitari possunt habere finem, Tu vero nequaquam?” (Proslogion), 5, 18 y 20 respectivamente. 
final de la obra ${ }^{74}$-. Todo esto parece confirmar nuestra lectura y está, además, en consonancia con la correspondencia e implicación mutua entre "esse-videre-amare" de la metafísica agustiniana que el Prior había asumido y declarado antes en el Monologion ${ }^{75}$. Por tanto, si Anselmo ha dejado ya patente que entiende de este modo y habitualmente la conexión "cogitareldiligere", no parece que tenga necesidad ninguna de explicitarla en el conciso enunciado del Argumento -y en este sentido, es significativo que autores posteriores a Anselmo, al hablar de modo explícito de una comprensión cordial y del acceso afectivo a la belleza, adopten expresiones fuertemente parecidas a la formulación del Proslogion ${ }^{76}$.

Una grave consecuencia de centrarse solo en el aspecto lógico del Argumento es que se lo recorta de su propio marco de comprensión, que es la relación con el Dios de Jesucristo. Pero cuando se atiende a la

74 "Utique tantum gaudebunt, quantum amabunt; tantum amabunt, quantum cognoscet. Quantum te cognoscent, Domine, tunc et quantum Te amabunt? [...] Oro, Deus, cognoscam Te, amem Te, ut gaudeam de Te. [...] Proficiat hic in me notitia tua, et ibi fiat plena; crescat amor tuus, et ibi sit plenus, ut hic gaudium meum sit in spe magnum, et ibi sit in re plenum". Proslogion, 26.

75 "Denique rationali naturae non est aliud esse rationalem, quam posse discernere iustum a non iusto, verum a non vero, bonum a non bono, magis bonum a minus bono. Hoc autem posse omnino inutile illi est et supervacuum, nisi quod discernit, amet aut reprobet, secundum verae discretionis iudicium. Hinc itaque satis patenter videtur omne rationale ad hoc existere, ut sicut ratione discretionis, aliquid magis vel minus bonum, sive non bonum iudicat, ita magis vel minus id amet aut respuat. Nihil igitur apertius quam rationale creaturam ad hoc esse factam, ut summam essentiam amet super omnia bona, sicut ipsa est summum bonum; immo ut nihil amet nisi illam aut propter illam, quia illa est bona per se, et nihil aliud est bonum nisi per illam. Amare autem eam nequit, nisi eius reminisce et eam studuerit intelligere. Clarum ergo est rationale creaturam totum suum posse et velle ad memorandum et intelligendum, et amandum summum bonum impendere debere, ad quod ipsum esse suum se cognoscit habere". Monologion, 68.

76 Cf. Hugo de SAn Víctor, De Arca Noe morali I, I (Patrologia Latina 176, Brepols, Turnhout 1854) col. 620 A: "[...] praecipue cum ipse talis sit, qui nequeat sciri et non amari. Tanta est enim species pulchritudinis eius ut qui eum potuerit videre, non possit non diligere". O Buenaventura de Bagnoregio, Itinerarium mentis in Deum, VI, 2: "[...] optimum quod simpliciter est quo nihil melius cogitari potest; et hoc tale sic est, quod non potest recte cogitari non esse, quia omnino melius est esse quam non esse; sic est, quod non potest recte cogitari, quin cogitetur trinum et unum". Ambas en la Red (consulta: 27/08/2020): http://www.documentacatholicaomnia.eu/20vs/104_migne_pl/1815-1875,_Migne,_Patrologia_Latina_176_ (AD_1854)_Universite_Catholique_Lille,_MLT.pdf http://www.archive.org/stream/doctorisseraphic05bona\#page/309/mode/1up. 
sustancia del Argumento es necesario ver que su carácter vital está en relación directa con el misterio de la Encarnación y la estructura metafísica que esta revela: la kenosis. En efecto, la iluminación del intelecto a la luz de la Verdad sucede no solo porque el Maestro interior hable en la conciencia ${ }^{77}$, sino porque la dinámica propia del conocimiento es en sí misma kenótica: partiendo de la experiencia de la propia realidad que se experimenta como asombrosa, bella, donada (esse), el sujeto que conoce (videre) debe vaciarse de sí para acoger lo distinto de sí, debe olvidarse de su propio juicio, de su propia idea para acoger lo que se le ofrece y se le muestra. Hay un aspecto de entrega, de renuncia, de sacrificio, es decir, de amor en el mismo acto de conocimiento (amare). No son tanto etapas sucesivas de un proceso, sino más bien aspectos del mismo acto de existir-conocer-amar. El Arquetipo es siempre el Hijo-Verbo y la Trinidad Divina ${ }^{78}$.

Si todo esto es así, entonces podemos reformular el argumento de acuerdo con sus categorías de fondo. Resultaría que:

1: Dios es aquello mayor de lo cual no puede existir-conocerse-amarse nada.

2: Dios es entonces aquello que más se ama: que se ama por encima de todas las cosas.

3: Pero lo que se ama sobre todas las cosas compromete y justifica la existencia de quien lo ama de este modo.

4: Es así que en su propia existencia el "insipiens" de hecho ama algo más que todas las demás cosas y por lo mismo ese objeto máximo de su máximo amor constituye la razón última que justifica su vida.

5: Por tanto, el “insipiens" tiene de hecho una razón última que justifica su vida, mayor/mejor de la cual no ama nada: La tiene de tal modo que negarla es quitarse a sí mismo el fundamento de su propia existencia.

Tiene esta razón "in intellectu" no solo como un mero contenido de conciencia, como una idea de "asentimiento nocional" ("nuda cogitatio", "peripheral belief"), ni como una palabra, ni siquiera la tiene como algo in-

Cf. Agustín de Hipona, De Magistro IX, 38.

78 Cf. Proslogion, 13 y 23; Monologion, 31; H. U. von BalThasar, Gloria, II, 231; Agustín de Hipona, De Trinitate, X, 11-12. 
telectualmente comprendido y aceptado, sino que la tiene en su entendimiento y en su corazón ("in corde suo") como existente fuera de su propia conciencia: vive por ella, vive para entregarse a eso que ama más que todas las cosas: por eso le presta un "asentimiento real" ("cogitatio cum assensu", "central belief"). Por tanto, el “insipiens" tiene, de hecho, un dios, y por más que no lo llame con ese nombre, hay algo que reconoce como sumamente valioso y por lo que afronta las dificultades y trabajos de cada día.

Tal vez parezca que esta reflexión va más en la línea del argumento del deseo natural y se aparta de la formulación lógica del Proslogion. Pensamos más bien que, si nuestra lectura es correcta, apuntaría precisamente a la intención de integrar los dos extremos: la especulación intelectual de los capítulos 2 y 3 arranca del deseo del corazón de ver a Dios, expresada en el capítulo 1, de modo que la formulación lógica no se refiere a meros conceptos puros inmanentes a la conciencia y coherentemente conectados sino a Aquello que puede justificar los anhelos más profundos del corazón, de manera que su conclusión lógica tenga también implicaciones vitales. Dado que el Prior de Bec se refiere explícita y profundamente en otras obras al "appetitus naturalis ad Deum"79, puede admitirse que tal idea esté también en el trasfondo del Proslogion, más aún cuando expresiones como "anhela/tengo-hambre/sed/deseo/ansioso de amor" (anhelatlesurio/sitio/desiderium/anxius amore), etc. abren la reflexión en el capítulo 1 y la cierran en los dos últimos ${ }^{80}$-como si, a modo de inclusión, indicara que este deseo-amor de ver-entender a Dios es el marco y horizonte de toda su reflexión-; lo cual le da ese sentido cristológico y escatológico que señala el padre Hubert y que "resuelve el enigma del hombre" 81 .

79 Cf. Monologion, 6; H. U. von Balthasar, Gloria, II, 226.

80 Cf. Proslogion, 1, 25 y 26.

81 "Como en el Monologion, la fe se une con el amor y la imagen (c. 1) y presenta un tinte escatológico (cc. 24 ss.). Además se trata de "entender". Intelligere es más que el solo entender intelectualmente. Es intus-legere, i.e. leer desde adentro, desde el corazón; es entrar en lo que se lee. Entender la Verdad es entonces fundirse en esa Verdad que es Cristo (Jn 14, 6). Cristo da sentido al Proslogion. Solamente con El podemos entender el famoso argumento del c. 2. Solamente con El podemos entender los últimos capítulos (cc. 24-26) donde está presente como "el Hijo" (26; $121,18)$, "el admirable consejero" $(26 ; 121,20)$. Con Cristo podemos acoger las verdades escatológicas: allí el conocimiento y el amor alcanzan su perfección. La fe viva crece en el amor para llegar a ser plena y vivir plenamente en la realidad del 
Si reformulamos el Argumento de acuerdo con todo esto y decimos que "Deus est Aliquid quo nihil maius diligi potest" (de lo que resulta que "Dios es aquello-que-se-ama-sobre-todas-las-cosas"), entonces en el corazón de la "Ratio Anselmi" se advierte una resonancia de Dt 6, 5: "Amarás al Señor tu Dios con todo tu corazón" (Diliges Dominum Deum tuum ex toto corde tuo); resonancia que hay que poner de nuevo en relación con su reverso (al menos intencional) que era el Salmo 14 (13): "Dixit insipiens in corde suo: non est Deus". De esta forma se descubre que, paradójicamente, el "insipiens" que dice "in corde suo: non est Deus", de súbito cae en la cuenta de la contradicción no ya lógica sino dramáticamente vital, en la que está, pues se descubre a sí mismo amando "ex toto corde" algo "mayor de lo cual no puede amar nada": amándolo como si fuera Dios.

Por eso -creemos- el argumento concluye y rige y vale: Es coherente, porque el "insipiens" tiene que reconocer que vive por una razón última de su existir. Vive para alcanzarla... Se ve igualmente que el Argumento no es "a priori", sino "a simultaneo", pues el "insipiens" reconoce que tiene un amor mayor del cual no puede amar nada en el mismo momento en que cae en la cuenta de lo que significa ese amor máximamente existente para él. No se trata de que el "insipiens" violente el paso del orden del pensar al orden del existir, sino que el "insipiens" encuentra unificados en su propia existencia esos dos órdenes cuando ve que vive por aquello que piensa y ama (cuando se piensa a sí mismo en su propia y real existencia). Y en la medida en que el pensamiento es también opción de vida, el paso del cogitare al esse es legítimo: decidimos y realizamos las cosas que hemos pensado, de acuerdo con la idea que teníamos de ellas - por eso es muy adecuado el ejemplo del pintor ${ }^{82}-$.

Con esto, san Anselmo enfrenta al "insipiens" a su contradicción lógica de reconocer que afirma la idea de un "Existente-máximamenteexistente" al que le niega la existencia, y también a su contradicción vital de vivir con un "amor mayor del cual no ama nada", un "dios" cuya existencia niega con los labios, pero admite en su corazón. El Prior da dos pasos más: Primero llevará al "insipiens" a analizar si la existencia de ese "dios" se da solo "in intellectu" o también "in re", para ver si es solo

cielo con Dios. Allí y solamente allí se resuelve el enigma del hombre” (A. HubERT,

"El enigma del hombre...", I, 2).

82 Cf. Proslogion, 2. 
una ilusión, una "proyección inmanente" (como creerán Feuerbach y las ideologías utópicas) o tienen consistencia real en "aliquid" trascendente al sujeto. Lo primero conduce a un solipsismo -individual o colectivosin salida. Lo segundo evita este riesgo, pues se dirige a algo distinto de uno mismo, pero puede derivar en idolatría subjetivista: el "insipiens" podría reconocer que ese "amor-mayor-del-cual-no-ama-nada" existe "in re", como su familia o su profesión ${ }^{83}$; este "aliquid" sería para él su "dios", mientras que otras personas podrían tener también sus propios "dioses", de modo que la "Ratio Anselmi" justificaría el politeísmo y el panteísmo -como quiere concluir Harwood, a nuestro parecer superficialmente y sin consistencia ${ }^{84}-$.

Pero estas conclusiones serían en falso, porque la "Ratio Anselmi" no termina en el capítulo 4, sino que luego hay otros veintidós. En ellos San Anselmo da el siguiente paso y guía al "insipiens" a un análisis crítico de ese "amor mayor del cual no ama nada" para ver si verdaderamente es "maius": si merece ser amado sobre todas las cosas. Nada que sea temporal es "maius" que algo eterno ${ }^{85}$ (por eso el "insipiens" tiene que descartar como "Verdadero Dios" (Verus Deus) a su familia o su profesión). Nada que sea solo justo o solo misericordioso puede ser "maius" de lo que es simultáneamente justo y misericordioso ${ }^{86}$. Solo es “maius" lo que es absolutamente trascendente ${ }^{87}$ y omnipotente ${ }^{88}$. El "Verus Deus" tiene que ser "maius" que cualquier Dios solitario y que una mera fuerza cósmica metafísica ${ }^{89}$, ya que la razón exige que la perfección de ese Existente sea tal que integre en unidad el Esse, el Videre y el Amare máximos, y por lo mismo que sea Unus et Trinitas ${ }^{90}$ (por eso, entre otras cosas, nos parece equivocado el artículo de Harwood citado antes). Si es Amor, tiene que amarnos y salvarnos ${ }^{91}$. Y si es Dios debe ser capaz de vencer el mal y vencerlo con el bien ${ }^{92}$ (esta era una de las condiciones que para la validez del

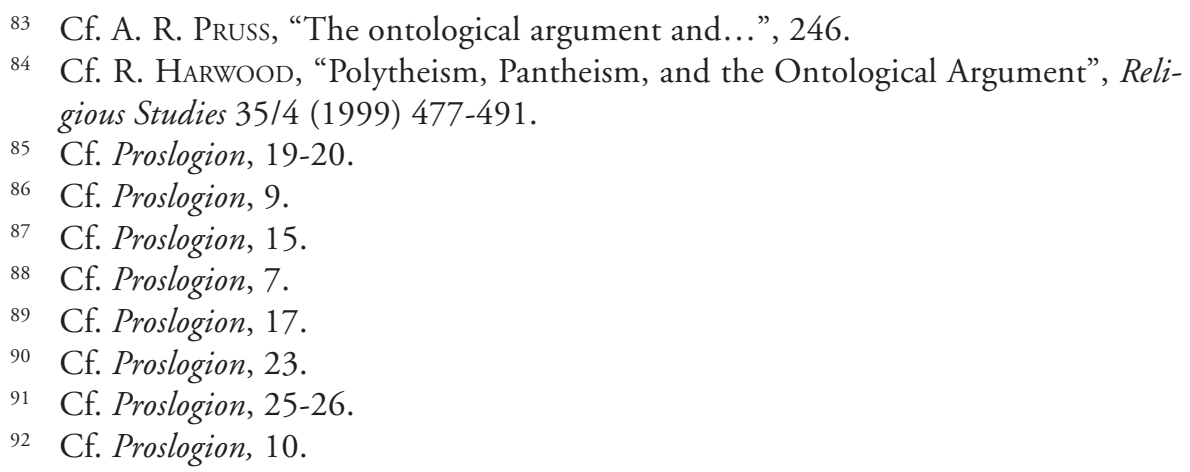


argumento apunta Pruss ${ }^{33}$ ). De esta forma, el análisis simultáneamente existencial-intelectual-cordial del Proslogion entero -y no solo de los primeros tres capítulos- es lo que puede llevar al "insipiens" a convencerse de la necesidad vital y lógica de la existencia de un "Dios-Amor mayor del cual no es posible pensar-amar nada".

\section{Conclusión}

Debemos llegar a las conclusiones. La primera es que quizás el Argumento de san Anselmo no es una simple teoría en torno a términos y definiciones, y la cuestión que abre no se resuelve diciendo sin más que "no se puede pasar del pensar al ser" o con ejemplos de islas perdidas y monedas alemanas, sino que es necesario triangular las dimensiones del esse y del intelligere con la del amare, como hace la tradición agustiniana. La segunda conclusión es que, de hecho, todos tenemos un "amor mayor del cual no amamos nada" que justifica nuestra existencia. El mérito de Anselmo es hacernos caer en la cuenta de que, primero, ese amor existe "in intellectu et in re"; segundo, que lo adoramos como si fuera el Dios por quien vivimos; tercero, que solo si es verdaderamente "maius" podemos identificarlo con el "Verus Deus"; y, cuarto, que solo en una relación real de amor "ex toto corde" con el "Verus Deus" captaremos el misterio de su Existencia en relación con el sentido de la nuestra. Por eso, la tercera conclusión es que, entendida así en el contexto de la tradición agustiniana que integra "esse, intellectus et cor", la "Ratio Anselmi" resulta "recta": consistente, verdadera y justa.

Para terminar, solo nos queda hacer un apunte sobre la identidad real del "insipiens" con quien dialoga san Anselmo: En el contexto de una Edad Media completamente creyente, parece anacrónico identificarlo con cualquier tipo de ateo. Anselmo, por su parte, nos pone en la pista adecuada: al inicio mismo de su obra nos confiesa que él (¡cristiano y monje!) es el verdadero "insipiens", que duda y a veces -por limitación, fragilidad, cansancio, dolor, o incluso por maldad y pecado- en lo profundo de su corazón puede llegar a negar que Dios exista. Por todo esto, el argumento es fuertemente dramático, vivencial, personal y revela en qué medida la pregunta por Dios es en realidad la pregunta por el sentido de la existencia humana, no en abstracto, sino en la existencia hu-

93 Cf. A. R. Pruss, “The ontological argument and...", 241 y 248. 
mana propia. Anselmo ha partido del "esse": la percepción de su propia realidad contingente y frágil, del deseo de su "memoria", de su corazón inquieto. Al buscar, ha entrado en el camino de la iluminación interior del "videre" y ha comprendido que Dios existe, y que la existencia de Dios está vinculada a la nuestra como su fundamento y origen. Esto le lleva a reconocer a Dios también como Bien absolutamente amable, de modo que se convierte a Él en la dimensión del "amare”. Y como el “insipiens" es igualmente todo hijo de Adán, el Argumento, mucho más que un ejercicio de sutil lógica escolástica, es una invitación razonada no solo para "admitir que Dios existe" sino para "amarlo sobre todas las cosas" (ex toto corde): es una verdadera "exhortación” (allocutio, pros-logion) a la santidad. Y así, el Proslogion es un servicio de caridad intelectual que nos hace el Prior de Bec. 